\title{
Qualidade das sementes de girassol de diferentes genótipos
}

\author{
Quality of sunflower seeds of different genotypes
}

\author{
Danúbia Aparecida Costa Nobre ${ }^{\mathrm{I}}$ Cândido Alves da Costa ${ }^{I}$ \\ Delacyr da Silva Brandão Junior ${ }^{\text {II }}$ José Carlos Fialho de Resende \\ Nicoletta Stefânia Dias da Silva Flávio" ${ }^{\text {II }}$
}

\section{RESUMO}

O girassol é uma das mais importantes culturas produtoras de óleo comestivel, portanto, o estudo foi desenvolvido com o objetivo de avaliar aspectos da qualidade física, fisiológica e sanitária das sementes de diferentes genótipos de girassol produzidas no Norte de Minas Gerais. As sementes foram avaliadas por meio das seguintes determinações e testes: teor de água, massa de 1000 sementes, biometria das sementes (comprimento, largura e espessura), teste de germinação, primeira contagem, indice de velocidade de germinação, teste de tetrazólio e sanidade das sementes, em delineamento inteiramente ao acaso. Nos diferentes genótipos, foi observada desuniformidade no tamanho e massa de sementes e, para os genótipos SYN 034A, SY 3840, SY 4065, HLA 06270, M 734 e SYN 039A constatou-se elevado vigor e viabilidade, enquanto que, o SYN 034A e SY 3840 tinham baixa qualidade por meio do teste de tetrazólio. Os fungos detectados nas sementes dos diferentes genótipos tiveram baixa influência sobre o vigor e germinação delas.

Palavras-chave: Helianthus annuus L., tamanho, germinação, vigor, sanidade.

\section{ABSTRACT}

The sunflower is one of the most important crops which produce edible oil, so the study was developed to evaluate aspects of the physical, physiological and sanitary seeds of different sunflower genotypes produced in the North of Minas Gerais. The seeds were evaluated using the following determinations and tests: water content, mass of 1000 seeds, seed biometrics (length, width and thickness), germination, first count, speed of germination, tetrazolium test and seed health, in a completely randomized design. In different genotypes observed uneven in size and mass of seeds and the genotypes SYN 034A, SY 3840, SY 4065, HLA 06270, M 734 and SYN 039A showed high vigor and viability, while the SYN $034 A$ and $S Y 3840$ showed low quality by the tetrazolium test. The fungi detected in seeds of different genotypes had low influence on the vigor and germination.

Key words: Helianthus annuus L., size, germination, vigor, health.

\section{INTRODUÇÃO}

O girassol é cultivado em vários países nos chamados solos marginais, muitas vezes em condições semiáridas, onde quase todos os anos um estresse abiótico está presente, atuando como um fator limitante na produção agrícola (ŠKORIĆ, 2009). No entanto, ainda são poucas as informações disponíveis acerca da escolha adequada do genótipo a ser utilizado em cada localidade.

Outro fator que pode ainda prejudicar a difusão da cultura do girassol em algumas regiões é a baixa qualidade fisiológica e sanitária das sementes, assim como a época de plantio (GOMES et al., 2006; OLIVEIRA et al., 2011). Desse modo, é indispensável a utilização de sementes de girassol com elevada qualidade, porque a semeadura com menor vigor produz plantas com menor fitomassa seca total e índice de área foliar, o que proporcionará menor taxa de crescimento da cultura (BRAZ \& ROSSETTO, 2009).

As sementes são o veículo que contém todas as inovações e os avanços tecnológicos, visando

\footnotetext{
'Universidade Federal de Viçosa (UFV), Av. PH Rolfs, s/n, Centro, 36570-000, Viçosa, MG, Brasil. E-mail: danubia_nobre@yahoo.com.br. Autor para correspondência.

IN Núcleo de Ciências Agrárias, Universidade Federal de Minas Gerais (UFMG), Montes Claros, MG, Brasil.

IIIEmpresa de Pesquisa Agropecuária de Minas Gerais (EPAMIG), Montes Claros, MG, Brasil. Recebido 17.09.12 Aprovado 06.02.15 Devolvido pelo autor 29.04.15 CR-2012-0863.R5
} 
a agregação de valor ao produto a ser transferido para o agricultor, representando, além disso, altos ganhos econômicos ao setor agrícola (BRASIL, 2011). Como a germinação das sementes é um atributo específico, característico para cada genótipo (RADIĆ et al., 2009), faz-se necessário a reunião de todos os atributos genéticos, físicos, fisiológicos e sanitários que contribuem para a formação de plantas vigorosas (POPINIGIS, 1985; SANTOS, 2009), capazes de promover uma rápida emergência e garantir o seu estabelecimento, com reflexos diretos na produtividade agrícola.

Nesse sentido, o objetivo no estudo foi avaliar aspectos da qualidade física, fisiológica e sanitária das sementes de diferentes genótipos de girassol, produzidas no norte de Minas Gerais.

\section{MATERIAL E MÉTODOS}

As sementes foram cultivadas em blocos casualizados com quatro repetições, totalizando 40 parcelas de $16,8 \mathrm{~m}^{2}$ cada e as plantas espaçadas em $0,70 \mathrm{~m}$, cuja semeadura foi realizada no período de safrinha (fevereiro a julho), do ano agrícola de 2011, na Fazenda Experimental da Empresa de Pesquisa Agropecuária de Minas Gerais (EPAMIG), no município de Nova Porteirinha, situado ao Norte de Minas Gerais.

Ao final do ciclo de produção, quando os capítulos encontravam-se no ponto de maturidade fisiológica, as sementes foram colhidas e encaminhadas ao Laboratório de Análise de Sementes do Instituto de Ciências Agrárias da Universidade Federal de Minas Gerais, na cidade de Montes Claros - MG, para realização das análises.

Para a avaliação da qualidade das sementes de girassol dos genótipos BRS G30, BRS G32, BRS G33, HLA 06270, M 734, SY 3840, SY 4065, SYN 034A, SYN 039A e V 70153, determinou-se o teor de água destas utilizando o método da estufa, a $105^{ \pm} 3^{\circ} \mathrm{C}$, durante 24 horas (BRASIL, 2009a), e foram utilizadas três repetições de 15 gramas para cada genótipo. Os resultados foram expressos em porcentagem.

A massa de mil sementes foi realizada por meio da pesagem de oito subamostras de 100 sementes puras, em balança de precisão $(0,0001 \mathrm{~g})$, conforme BRASIL (2009a), com os resultados expressos em gramas. As medidas biométricas das sementes foram obtidas com os dados de comprimento (em sentido longitudinal), largura (em sentido transversal) e espessura das sementes, realizadas com o auxílio de um paquímetro digital $(0,01 \mathrm{~mm})$, utilizando-se quatro repetições de 25 sementes para cada genótipo.
Para o teste de germinação, utilizou-se o método do rolo de papel toalha (tipo Germitest ${ }^{\circledR}$ ), umedecido com água destilada na proporção de 2,5 vezes a massa seca do papel, em quatro repetições de 50 sementes para cada genótipo. Os rolos foram colocados em câmara de germinação do tipo Biochemical Oxigen Demand (B.O.D), regulada à temperatura constante de $25^{\circ} \mathrm{C}$ e fotoperíodo de 12 horas, com avaliações realizadas no quarto e décimo dia após a instalação do teste; ao final do teste, foram computadas as plântulas normais, anormais e sementes duras. Em conjunto com o teste de germinação, realizou-se o teste de primeira contagem de germinação, obtido pelo número de plântulas normais, no quarto dia após a montagem do teste, cujos resultados foram expressos em porcentagem (BRASIL, 2009a).

$\mathrm{O}$ índice de velocidade de germinação foi conduzido anotando-se diariamente o número de sementes germinadas, durante os dez dias de avaliação. Com os dados diários do número de sementes germinadas, dividido pelo respectivo número de dias transcorridos a partir de semeadura, foi calculado o índice de velocidade de germinação, empregando-se a fórmula proposta por MAGUIRE (1962).

Para o teste de tetrazólio, as sementes foram submetidas ao pré-condicionamento para a remoção do tegumento, por meio da imersão direta em $200 \mathrm{~mL}$ de água, durante 18 horas a $20^{\circ} \mathrm{C}$. Logo após, os embriões foram imersos na solução de 2,3,5 trifenil cloreto de tetrazólio a $1,0 \%$ e mantidas no escuro a $30^{\circ} \mathrm{C}$ por três horas. Os embriões foram então lavados em água destilada e analisados individualmente (BRASIL, 2009a), por meio das cinco classes de viabilidade e vigor. $\mathrm{O}$ vigor foi decidido pelo somatório do número de sementes das classes 1 e 2 e a viabilidade de 1 a 3 (BHERING et al., 2005).

$\mathrm{O}$ teste de sanidade foi realizado em quatro repetições de 25 sementes para cada genótipo, pelo método do papel mata-borrão em caixa gerbox, com uma camada fina de agar-agar a $1,5 \%$. As caixas com as sementes foram colocadas em câmara de germinação tipo B.O.D. por 24 horas, sendo, em seguida, colocadas em congelador, com o objetivo de impedir a germinação das sementes. Logo após, foram transferidas para a B.O.D. com lâmpadas de luz fluorescente branca e fotoperíodo de 12 horas, durante cinco dias, a $20 \pm 2^{\circ} \mathrm{C}$ (BRASIL, 2009b). Após o período de incubação, as sementes foram analisadas em lupa estereoscópica e microscópio óptico para a identificação dos fungos.

O delineamento experimental utilizado para realização dos testes foi o inteiramente casualizado. 
Os dados em porcentagem foram transformados em arco seno $\sqrt{x / 100}$ e os de contagem de fungos em $\sqrt{x+0,5}$. Em seguida, foram submetidos à análise de variância e as características significativas submetidas ao teste Scott-Knott, ao nível de 5\% de probabilidade.

\section{RESULTADOS E DISCUSSÃO}

As médias do teor de água das sementes de girassol (Tabela 1) dos genótipos BRS G30, SY 4065, HLA 06270, BRS G33 e SYN 039A foram elevadas e diferiram $(\mathrm{P}<0,05)$ das demais. ALBUQUERQUE et al. (2001) e THOMAZINI \& MARTINS (2011), em estudos realizados com diferentes genótipos e locais, encontraram valores próximos aos relatados na presente pesquisa. De acordo com LEITE et al. (2005), o teor de água ideal para aquênios de girassol se encontra na faixa de 5 a 10\%, logo, pode-se constatar que não houve interferência dessa variável nas análises de qualidade das sementes no presente estudo.

Os resultados para a massa média de 1000 sementes demonstram diferenças entre os genótipos de girassol (Tabela 1), com maior média obtida para o genótipo BRS G30, que diferiu em 19,5g em comparação com a menor média (SYN 039A).

A massa seca das sementes é o resultado da capacidade da planta de suprir nutrientes até o limite potencial estabelecido para cada cultivar, pois, em geral, há uma grande diversidade de respostas especialmente associadas ao número de aquênios previamente fixados (ZAGONEL \&
MUNDSTOCK, 1991). Para SILVA et al. (2011), a qualidade física é afetada pela localização das sementes na inflorescência, cujas mais pesadas se encontram na periferia e as do centro são as sementes mais leves.

Para a biometria das sementes dos genótipos de girassol, maior média de comprimento foi observada no M 734, diferindo-se dos demais; as sementes dos genótipos BRS G30, SY 3840, BRS G33 e o M734 expressaram as maiores médias de largura e não diferiram entre si. Estes mesmos genótipos, com acréscimo do HLA 06270, foram os de maior espessura. Diante do exposto, o genótipo M 734 foi aquele com as maiores sementes.

O tamanho das sementes de girassol utilizadas na semeadura não influencia a produção, nem tampouco a qualidade delas, avaliada por meio do peso de 100 sementes, da germinação, do vigor e do teor de óleo, conforme relatado por ADAMO et al. (1984). No entanto, sementes de girassol com menor largura $(4,5 \mathrm{~mm})$ tiveram maior teor de água e matéria seca nas diferentes épocas de produção, além de menor porcentagem de plântulas normais (OLIVEIRA et al., 2011). No presente estudo, para as sementes dos genótipos de girassol que obtiveram largura inferior a $4,5 \mathrm{~mm}$ não se verificaram esses resultados, conforme expresso nas tabelas 1 e 2 . Portanto, o tamanho, não interfere na qualidade das sementes.

Sabendo-se que há variações nas sementes de girassol, quanto ao comprimento, à largura e à espessura, esse fato pode ainda dificultar o trabalho

Tabela 1 - Teor de água (T.A.), massa de mil sementes (M 1000), comprimento (C), largura (L) e espessura (E) de sementes dos genótipos de girassol colhidos em Nova Porteirinha, Norte de Minas Gerais.

\begin{tabular}{|c|c|c|c|c|c|}
\hline \multirow{2}{*}{ Genótipos } & \multicolumn{5}{|c|}{-Variáveis-- } \\
\hline & T.A. (\%) & M $1000(\mathrm{~g})$ & $\mathrm{C}(\mathrm{mm})$ & $\mathrm{L}(\mathrm{mm})$ & $\mathrm{E}(\mathrm{mm})$ \\
\hline BRS G30 & $7,7 \mathrm{a}$ & $58,5 \mathrm{a}$ & $10,3 \mathrm{c}$ & $5,0 \mathrm{a}$ & $3,2 \mathrm{a}$ \\
\hline SYN 034A & $6,7 \mathrm{~b}$ & $44,0 \mathrm{e}$ & $10,9 \mathrm{~b}$ & $4,5 \mathrm{~b}$ & $2,7 \mathrm{~b}$ \\
\hline SY 3840 & $6,3 \mathrm{~b}$ & $43,0 \mathrm{e}$ & $10,8 \mathrm{~b}$ & $5,5 \mathrm{a}$ & $3,1 \mathrm{a}$ \\
\hline SY 4065 & $7,6 \mathrm{a}$ & $47,0 \mathrm{c}$ & $10,9 \mathrm{~b}$ & $4,3 \mathrm{~b}$ & $2,6 \mathrm{~b}$ \\
\hline HLA 06270 & $7,3 \mathrm{a}$ & $54,0 \mathrm{~b}$ & $10,3 \mathrm{c}$ & $4,5 \mathrm{~b}$ & $3,0 \mathrm{a}$ \\
\hline BRS G33 & $7,4 \mathrm{a}$ & $55,0 \mathrm{~b}$ & $9,7 \mathrm{~d}$ & $5,2 \mathrm{a}$ & $3,1 \mathrm{a}$ \\
\hline V 70153 & $6,5 \mathrm{~b}$ & $45,0 \mathrm{~d}$ & $9,5 \mathrm{~d}$ & $4,3 \mathrm{~b}$ & $2,9 \mathrm{a}$ \\
\hline M 734 & $6,7 \mathrm{~b}$ & $54,2 \mathrm{~b}$ & $11,6 \mathrm{a}$ & $5,2 \mathrm{a}$ & $2,9 \mathrm{a}$ \\
\hline BRS G32 & $6,9 \mathrm{~b}$ & $49,1 \mathrm{c}$ & $9,9 \mathrm{~d}$ & $4,6 \mathrm{~b}$ & $2,8 \mathrm{~b}$ \\
\hline SYN 039A & $7,4 \mathrm{a}$ & $39,0 \mathrm{f}$ & $10,2 \mathrm{c}$ & $4,4 \mathrm{~b}$ & $2,6 \mathrm{~b}$ \\
\hline Médias & 7,05 & 48,88 & 10,41 & 4,75 & 2,79 \\
\hline CV (\%) & 7,05 & 4,88 & 2,14 & 11,78 & 4,67 \\
\hline
\end{tabular}

Médias seguidas de mesma letra, na coluna, não diferem estatisticamente entre si pelo teste Scott-Knott a 5\% de probabilidade.

Ciência Rural, v.45, n.10, out, 2015. 
Tabela 2 - Germinação (G), primeira contagem (PC), índice de velocidade de germinação (IVG), plântulas anormais (PA), sementes duras (SD), tetrazólio vigor (TZ 1-2) e viabilidade (TZ 1-3), verificados pelos genótipos de girassol, colhidos em Nova Porteirinha, Norte de Minas Gerais.

\begin{tabular}{|c|c|c|c|c|c|c|c|}
\hline \multirow{2}{*}{ Genótipos } & \multirow{2}{*}{ G (\%) } & \multirow[b]{2}{*}{ PC (\%) } & \multirow[b]{2}{*}{ IVG } & \multirow{2}{*}{$\begin{array}{l}\text { ariáveis- } \\
\text { PA (\%) }\end{array}$} & \multirow[b]{2}{*}{$\mathrm{SD}(\%)$} & \multirow[b]{2}{*}{ TZ 1-2 (\%) } & \multirow[b]{2}{*}{ TZ 1-3 (\%) } \\
\hline & & & & & & & \\
\hline BRS G30 & $70,0 \mathrm{~b}$ & $61,5 \mathrm{~b}$ & $17,1 \mathrm{~d}$ & $2,5 \mathrm{~b}$ & $12,0 \mathrm{a}$ & $58,0 \mathrm{~b}$ & $58,0 \mathrm{~b}$ \\
\hline SYN $034^{\mathrm{a}}$ & $93,5 \mathrm{a}$ & $93,5 \mathrm{a}$ & $24,9 \mathrm{a}$ & $3,2 \mathrm{~b}$ & $0,0 \mathrm{~b}$ & $45,0 \mathrm{c}$ & $51,0 \mathrm{c}$ \\
\hline SY 3840 & 86,0 a & $79,5 \mathrm{a}$ & $23,4 \mathrm{a}$ & $6,2 \mathrm{~b}$ & $0,7 \mathrm{~b}$ & $30,0 \mathrm{~d}$ & $40,0 \mathrm{~d}$ \\
\hline SY 4065 & 89,0 a & $87,5 \mathrm{a}$ & $24,8 \mathrm{a}$ & $5,0 \mathrm{~b}$ & $0,5 \mathrm{~b}$ & $57,0 \mathrm{~b}$ & $61,0 \mathrm{~b}$ \\
\hline HLA 06270 & $93,0 \mathrm{a}$ & $91,5 \mathrm{a}$ & $24,9 \mathrm{a}$ & $3,3 \mathrm{~b}$ & $0,2 \mathrm{~b}$ & $56,0 \mathrm{~b}$ & $56,0 \mathrm{~b}$ \\
\hline BRS G33 & $74,0 \mathrm{~b}$ & $55,0 \mathrm{~b}$ & $16,9 \mathrm{~d}$ & $4,0 \mathrm{~b}$ & $8,5 \mathrm{a}$ & $58,0 \mathrm{~b}$ & $60,0 \mathrm{~b}$ \\
\hline V 70153 & $85,5 \mathrm{a}$ & $62,0 \mathrm{~b}$ & $18,4 \mathrm{c}$ & $4,2 \mathrm{~b}$ & $2,7 \mathrm{~b}$ & $68,0 \mathrm{a}$ & $68,0 \mathrm{a}$ \\
\hline M 734 & 89,5 a & $87,5 \mathrm{a}$ & $24,6 \mathrm{a}$ & $5,0 \mathrm{~b}$ & $0,2 \mathrm{~b}$ & $64,0 \mathrm{a}$ & $64,0 \mathrm{a}$ \\
\hline BRS G32 & $76,5 \mathrm{~b}$ & $63,5 \mathrm{~b}$ & $21,0 \mathrm{~b}$ & $9,5 \mathrm{a}$ & $1,7 \mathrm{~b}$ & $65,0 \mathrm{a}$ & $69,0 \mathrm{a}$ \\
\hline SYN 039A & $88,5 \mathrm{a}$ & $86,0 \mathrm{a}$ & $24.8 \mathrm{a}$ & $4,5 \mathrm{~b}$ & $1,0 \mathrm{~b}$ & $61,0 \mathrm{~b}$ & $65,0 \mathrm{a}$ \\
\hline Médias & 84,55 & 76,75 & 22,08 & 7,74 & 2,75 & 56,20 & 59,20 \\
\hline CV (\%) & 8,69 & 13,58 & 2,33 & 23,96 & 58,65 & 8,42 & 7,99 \\
\hline
\end{tabular}

Médias seguidas de mesma letra, na coluna, não diferem estatisticamente entre si pelo teste Scott-Knott a 5\% de probabilidade.

das semeadoras, podendo causar prejuízo pela desuniformidade na distribuição das sementes no sulco (MARCOS FILHO et al., 1986). Portanto, deve-se atentar para o fato de as características biométricas de sementes serem bastante variáveis, em função das condições ambientais durante a sua formação, das condições de armazenamento e das características genéticas das matrizes, o que pode explicar os resultados obtidos.

Diante do exposto, pode-se afirmar que a massa de sementes e a sua biometria são características relacionadas aos genótipos e a sua adaptação ao local de produção, não interferindo na qualidade das sementes.

$\mathrm{Na}$ tabela 2, observa-se que os valores médios do teste de germinação e primeira contagem, quando analisados juntamente, apontaram a maioria dos genótipos com sementes de alta viabilidade e vigor, exceto o V 70153, com baixo vigor. Dentre esses genótipos, nos materiais BRS G30, BRS G32 e BRS G33, constataram-se baixas médias e não houve diferenças entre eles. Os valores médios observados na presente pesquisa foram próximos aos descritos por BRAZ \& ROSSETTO (2009). Nota-se que a similaridade obtida nos teste de vigor e germinação estão atrelados à própria qualidade dos genótipos.

Os testes de vigor, pela primeira contagem e índice de velocidade de germinação (IVG), proporcionaram informações semelhantes a do teste de germinação, sugerindo alta sensibilidade destes para a separação, em diferentes níveis de qualidade fisiológica, dos genótipos avaliados.

Para alguns genótipos, esses resultados não foram semelhantes à viabilidade determinada pelo teste de tetrazólio (Tabela 2), em que se identificou o genótipo BRS G32 como de elevado vigor e viabilidade (classes 1-2 e 1-3), uma vez que suas médias foram inferiores para o teste de germinação, primeira contagem e índice de velocidade de germinação. Ao contrário disso, em outros materiais, como o SY 3840, verificaram-se altas médias de germinação e vigor, no entanto, baixa viabilidade e vigor pelo teste de tetrazólio. Dessa forma, é importante ressaltar ainda que maiores médias de sementes duras foram obtidas nos genótipos BRS G33 e BRS 30, enquanto no BRS G32 verificaram-se as maiores médias de plântulas anormais, o que pode confirmar a baixa qualidade fisiológica das sementes nestes genótipos.

No presente estudo, os testes para determinar a qualidade fisiológica das sementes foram realizados imediatamente após a colheita, o que pode explicar o elevado número de sementes duras, para alguns genótipos, uma vez que, há diferença no ciclo de produção dos materiais, sendo alguns mais precoces que outros. Portanto, as sementes de girassol com baixa germinação, possivelmente, estavam dormentes ou duras.

A viabilidade de sementes de girassol, armazenadas por 20 anos, foi avaliada e observou-se acentuada redução na germinação. Em contradição, ao 
utilizar o teste de tetrazólio, percebeu-se alta capacidade de germinação (SEILER, 2010). Isso sugeriu que os aquênios estavam apenas dormentes, portanto, os resultados do presente estudo podem ser confirmados com a presença de dormência inicial nos aquênios de girassol, uma vez que as sementes foram colhidas e, em seguida, submetidas aos testes de qualidade.

Outro fator de fundamental importância para a qualidade das sementes é a sanidade delas, pois, para LEITE (1997), a expansão da cultura do girassol pode ser prejudicada, entre outros fatores, pela presença de doenças causadas por vírus, bactérias e fungos. Do ponto de vista ecológico, os fungos podem ser agrupados em organismos de campo, com predominância de espécies fitopatogênicas e organismos de armazenamento, com pequeno número de espécies que deterioram as sementes (BARROCAS \& MACHADO, 2010), reduzindo, assim, o potencial de armazenamento e, por consequência, a germinação.

Os dados referentes à presença de fungos nas sementes dos genótipos estão na tabela 3, observando-se que, quanto ao gênero Aspergillus spp., as médias foram superiores para BRS G30, SY4065, M 734 e BRS G32. Para o gênero Alternaria spp., os genótipos nos quais houve maiores incidências foram SYN 034A, SY 3840, HLA 06270, BRS G33 e V 70153, em que se observou efeito significativo $(\mathrm{P}<0,05)$, não diferindo entre si. No gênero Curvularia sp. houve elevada incidência apenas para as sementes do V 70153, diferindo-se dos outros genótipos.
O Fusarium sp. estava presente apenas no BRS G30. Neste e no BRS G32, observou-se ainda a presença de Penicillium sp., com as maiores médias e diferentes dos demais genótipos para os genêros em questão. As maiores médias do Rhizopus sp. foram no genótipo SYN 039A e com médias intermediárias para os genótipos BRS G33 e BRS G32, diferindo dos demais. Segundo BARRETO et al. (2004), fungos do gênero Rhizopus podem afetar as sementes, ocasionando a redução da germinação e do vigor. No entanto, esse fato não foi observado no presente estudo.

As sementes de genótipos de girassol, cultivados em três municípios do Maranhão, estavam com altos índices de Fusarium sp. e Alternaria spp. (GOMES et al., 2008). Esses gêneros também foram observados na presente pesquisa, porém, parecem não ter promovido redução na qualidade das sementes porque a germinação atingiu médias de 70 a $93 \%$.

Apesar da diferença significativa nos resultados de contagem de fungos nas sementes de girassol, alguns patógenos parecem não ter influenciado o potencial fisiológico, indicando que as sementes produzidas no Norte de Minas Gerais eram de elevada qualidade, pois, mesmo as sementes dos genótipos com maior incidência de fungos, como Aspergillus e Rhizopus eram vigorosos e com boa germinação $(>70 \%)$. Apesar da comprovação do efeito negativo sobre a germinação e o vigor de sementes na presença desses patógenos (BRHATTACHARYA \& RAHA, 2002; PEREIRA

Tabela 3 - Incidência de fungos em sementes de genótipos de girassol, em Nova Porteirinha, Norte de Minas Gerais.

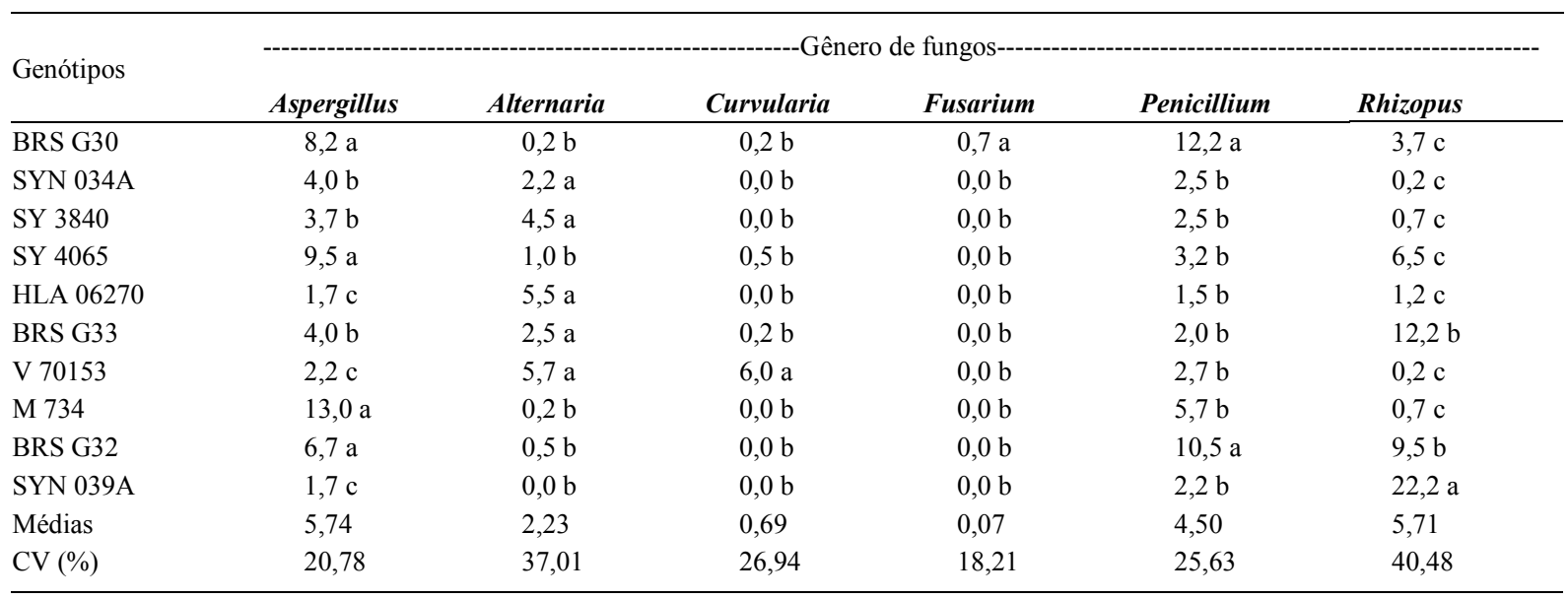

Médias seguidas de mesma letra na coluna, não diferem estatisticamente entre si pelo teste Scott-Knott a 5\% de probabilidade.

Ciência Rural, v.45, n.10, out, 2015. 
et al., 2010), vale ressaltar que a presença do Aspergillus nas sementes pode não ter promovido danos na qualidade delas, uma vez que este fungo pode elevar-se com o tempo de armazenamento das sementes, o que não foi realizado neste estudo.

O grau de severidade das doenças fúngicas em girassol varia de acordo com os genótipos e existem acessos provavelmente mais suscetíveis e tolerantes a essas infecções, conforme relatado por GOMES et al. (2008). Portanto, para a presente pesquisa, ainda há necessidade de se avaliarem os genótipos em estudo, uma vez que, em alguns, as médias foram mais baixas, em relação a outros, quando cultivadas no Norte de Minas Gerais; podendo ainda esses resultados estarem relacionados ao ciclo da cultura e à época de colheita, sendo necessária a confirmação da suscetibilidade, tolerância e ou da resistência desses genótipos frente às doenças fúngicas que acometem a cultura.

\section{CONCLUSÃO}

Nos diferentes genótipos, há desuniformidade no tamanho e massa de sementes e, naqueles genótipos SYN 034A, SY 3840, SY 4065, HLA 06270, M 734 e SYN 039A o vigor e viabilidade são elevados, enquanto que, os SYN 034A e SY 3840 são de baixa qualidade pelo teste de tetrazólio.

Os fungos detectados nas sementes dos diferentes genótipos têm baixa influência sobre o vigor e a germinação delas.

\section{REFERÊNCIAS}

ADAMO, P.E. et al. Influência do tamanho na produção e qualidade de sementes de girassol. Revista Brasileira de Sementes, v.6, n.3, p.9-14, 1984

ALBUQUERQUE, A.C.F. et al. Testes de condutividade elétrica e de lixiviação de potássio na avaliação da qualidade fisiológica de sementes de girassol. Revista Brasileira de Sementes, v.23, n.1, p.1-8, 2001. Disponível em: <http://www.abrates.org.br/revista/ $\operatorname{artigos} / 2001 / \mathrm{v} 23 n 1 /$ artigo01.pdf $>$. Acesso em: 20 ago. 2012.

BARRETO, A.F. et al. Qualidade fisiológica e a incidência de fungos em sementes de algodoeiro herbáceo tratadas com estratos de agave. Revista de Oleaginosas e Fibrosas, v.8, n.2/3, p.839849, 2004.

BARROCAS, E.N.; MACHADO, J.C. Introdução a patologia de sementes e testes convencionais de sanidade de sementes para deteç̧ão de fungos fitopatogênicos. Informativo ABRATES, v. 20, n.3, p.74-77, 2010.

BHERING, M.C. Adequação da metodologia do teste de tetrazólio para avaliação da qualidade fisiológica de sementes de melancia.
Revista Brasileira de Sementes, v.27, n.1, p.176-182, 2005. Disponível em: <http://www.scielo.br/pdf/rbs/v27n1/25196.pdf>. Acesso em: 23 ago. 2012.

BRASIL. Ministério da Agricultura, Pecuária e Abastecimento. Regras para análise de sementes. Secretaria de Defesa Agropecuária. Brasília: MAPA/ACS, 2009a. 395p.

BRASIL. Ministério da Agricultura, Pecuária e Abastecimento. Manual de análise sanitária de sementes. Secretaria de Defesa Agropecuária. Brasília: MAPA/ACS, 2009b. 200p.

BRASIL. Ministério da Agricultura Pecuária e Abastecimento. Guia de inspeção de campos para produção de sementes. Secretaria de Defesa Agropecuária. 3.ed. rev. e atual. Brasília: Mapa/ACS, 2011. 41p.

BRAZ, M.R.S.; ROSSETTO, C.A.V. Correlação entre testes para avaliação da qualidade de sementes de girassol e emergência das plântulas em campo. Ciência Rural, v.39, n.7, p.2004-2009, 2009. Disponível em: <http://www.scielo.br/scielo.php?pid=S0103$84782009000700008 \&$ script $=$ sci_arttext $>$. Acesso em: 15 jun. 2012. doi: 10.1590/S0103-84782009005000146.

BRHATTACHARYA, K.; RAHA, S. Deteriorative changes of maize, groundnut and soybean seeds by fungi in storage. Mycopathologia, v.155, n.3, p.135-141, 2002.

GOMES, D.P. et al. Qualidade fisiológica e sanitária de sementes de girassol produzidas na região de Timon, Maranhão. Summa Phytopathologica, v.32, n.3, p.291-292, 2006. Disponível em: $\quad<$ http://www.scielo.br/scielo.php?script=sci_arttext;pid $=$ S0100-54052006000300016>. Acesso em: 13 nov. 2012.

GOMES, D.P. et al. Sanidade de sementes de girassol provenientes de três municípios do estado do Maranhão. Revista Caatinga, v.21, n.1, p.55-63, 2008. Disponível em: $<$ http://redalyc.uaemex. $\mathrm{mx} / \mathrm{src} /$ inicio/artpdfred.jsp? $\mathrm{icve}=237117576008>$. Acesso em: 15 ago. 2012 .

LEITE, R.M.V.B.C. Doenças do girassol. Londrina: EMBRAPACNPSo, 1997. 68p. (Circular Técnica, 19).

LEITE, R.M.V.B.C. et al. Girassol no Brasil. Empresa Brasileira de Pesquisa Agropecuária. Londrina: EMBRAPACNPSo, 2005. p.641.

MAGUIRE, J.D. Speed of germination-aid in selection and evaluation for seedling emergence and vigor. Crop Science, v.2, n.1, p.176-177, 1962.

MARCOS FILHO, J. et al. Tamanho da semente e desempenho do girassol: III. Comportamento das plantas em campo. Revista Brasileira de Sementes, v.8, n.2, p.33-43, 1986.

OLIVEIRA, R.B. et al. Qualidade fisiológica de cipselas de girassol em função de largura e época de semeadura. Revista Brasileira de Sementes, v.33, n.3, p.435-446, 2011. Disponível em: <http://www.scielo.br/pdf/rbs/v33n3/06.pdf>. Acesso em: 25 mai. 2015.

PEREIRA, E.L. et al. Contaminação de sementes de amendoim, inoculadas por Aspergillus secção Flavi, influenciada pelo genótipo, pela área de cultivo e pelos isolados. Ciência e Agrotecnologia, v.34, n.4, p.853-859, 2010. Disponível em: <http://www.scielo.br/scielo.php?pid=S141370542010000 
400009; script $=$ sci_arttext $>$. Acesso em: 01 jan. 2012. doi: 10.1590/S1413-70542010000400009.

POPINIGIS, F. Fisiologia da semente. Brasília: AGIPLAN, 1985. 289p.

RADIĆ, V. et al. Interdependence of sunflower seed quality parameters. Helia, v.32, n.50, p.157-164, 2009.

SEILER, G.J. Germination and viability of wild sunflower species achenes stored at room temperature for 20 years. Seed Science and Technology, v.38, n.3, p.786-791, 2010.

SILVA, H.P. et al. Qualidade de sementes de Helianthus annuus L. em função da adubação fosfatada e da localização na inflorescência. Ciência Rural, v.41, n.7, p.1160-1165, 2011. Disponível em: < http://www.scielo.br/pdf/cr/v41n7/a4711cr4289. pdf $>$. Acesso em: 10 jul. 2012.
SANTOS, C.J.R. Secagem de sementes de girassol via radiação infravermelho e convecção forçada de ar aquecido. 2009.

75f. Dissertação (Mestrado em Engenharia de Processos) Universidade Tiradentes. Aracajú, Se.

ŠKORIĆ, D. Sunflower breeding for resistance to abiotic stresses. Helia, v.32, n.50, p.1-16, 2009.

THOMAZINI, A.; MARTINS, L.D. Qualidade física e fisiológica de sementes de girassol (Helianthus annuus L.) cultivar 'MG2' em condições de casa de vegetação e laboratório. Enciclopédia Biosfera, v.7, n.12, p.1-9, 2011. Disponível em: <http://www. conhecer.org.br/enciclop/2011a/agrarias/qualidade $\% 20$ fisica $\% 20$ e\%20fisiologica.pdf>. Acesso em: 15 ago. 2012.

ZAGONEL, J.; MUNDSTOCK, C.M. Doses e épocas de aplicação de nitrogênio em cobertura em duas cultivares de girassol. Pesquisa Agropecuária Brasileira, v.26, n.9, p.1487-1492, 1991. 